\title{
Have China's Unconverted Research Institutes Been Left Behind?
}

\author{
By
}

Renai Jiang, Daniel L. Tortorice, and Zhaohui Xuan

December 2019

\section{COLLEGE OF THE HOLY CROSS, DEPARTMENT OF ECONOMICS FACULTY RESEARCH SERIES, PAPER NO. 19-10*}

Department of Economics and Accounting College of the Holy Cross

Box 45A

Worcester, Massachusetts 01610

(508) 793-3362 (phone)

(508) 793-3708 (fax)

https://www.holycross.edu/academics/programs/economics-and-accounting

*All papers in the Holy Cross Working Paper Series should be considered draft versions subject to future revision. Comments and suggestions are welcome. 


\title{
Have China’s Unconverted Research Institutes Been Left Behind?* Renai Jiang ${ }^{\dagger}$, Daniel L Tortorice ${ }^{\ddagger}$ and Zhaohui Xuan ${ }^{+}$
}

November 2019

\begin{abstract}
Beginning in 1999, the Chinese government initiated a substantial restructuring of its roughly 4,000 research institutes. While many were given specific classifications to designate their institute objectives, many were left unconverted. We use a novel, fifteen-year panel dataset on China's system of research institutes to examine if unconverted institutes were disadvantaged relative to their converted counterparts. Unconverted institutes had a higher risk of exiting the research institute system and lower productivity growth than converted research institutes. However, their revenue growth kept pace with converted institutes and they continued to patent at similar rates. Finally, their publication of scientific papers declined relative to converted institutes. We conclude that the restructuring program has not left the unconverted institutes behind.
\end{abstract}

JEL Code: O31, O32, O38

Keywords: China, R\&D, Research Policy, Patenting, Research Institutes

\footnotetext{
* We gratefully acknowledge the assistance of the Ministry of Science and Technology (MOST) in allowing access to the data and patiently answering our many. We thank Gary Jefferson and members of the Holy Cross Department of Economics for many helpful conversations and suggestions. Any errors are our own.

† School of Economics and Finance, Xi’an Jiaotong University, Xi’an 710061, China, jiangrenai@xjtu.edu.cn

‡ Department of Economics and Accounting, College of the Holy Cross, 1 College St, Worcester MA, 01610, dtortori@holycross.edu, 15087933873

+ Institute of S\&T Statistics and Analysis, Chinese Academy of Science and Technology for Development, Beijing 100038,China, xuanzh@casted.org.cn
} 


\section{Introduction}

In light of the increasing importance of research and development (R\&D) in its economy, China initiated a restructuring of its vast system of research institutes. This collection of more than 4,000 institutes spans every province and industry within the country. However, the central government had substantial concerns that the sector was inefficient and over-reliant on government funding. To remedy these concerns, the Ministry of Science and Technology began a restructuring program which aimed to clarify the role of the institutes. Institutes were reclassified as science and technology (S\&T) enterprises, non-profit research institutes, or non-profit, non-research institutes. However, the majority of institutes remained unconverted. It is with these institutes the present paper is primarily concerned. Specifically, we investigate if unconverted institutes struggled relative to their converted brethren.

We use detailed administrative data on the research institutes to examine this question. We find no clear and substantial disadvantage to the institutes that were not converted. In terms of revenue and patenting, the unconverted showed no different levels of growth than the non-profit research institutes. On the other hand, unconverted research institutes were at a higher risk of exiting the research institute system. Additionally, their paper production and productivity exhibited slower growth relative to converted institutes.

There is little research on China's system of research institutes. Zhong and Yang (2007) discuss the institutes along with a broader discussion of China's S\&T policies and Conroy (1982) provides a history of the sector as does Yuan (2005) who also describes current and past reforms of the sector. Hu and Matthews (2008) suggest that research institutes have become more aligned with the industrial sector post restructuring (see also Jiang et. al. 2016), however, they argue that universities are still the most important source of innovative activities in China. Finally, Li (2009) and Guan et al (2005) document collaboration between private firms (both domestic and foreign) and universities and research institutes.

In Jiang et. al. (2016), we used propensity score and event study methodologies to identify the casual impact that the restructuring had on the converted institutes, finding that the reform succeeded in refocusing the more commercially oriented institutes and improving productivity. This current paper differs from that paper in specifically examining what has happened to the 
unconverted institutes. Additionally, in this paper we are able to view firm exits and the whole universe of institutes (the previous paper required us to use only a balanced sample) as so we are able to examine the evolution of the unconverted institutes exit probability over time.

To the best of our knowledge our paper is the first to examine the fate of unconverted research institutes. Our work is also unique in the literature for its quantitative scope. In this paper, we exploit a 15-year panel dataset on over 4,000 research institutes. Additionally, we use a wide variety of both input and output variables in the analysis.

Analysis of China's research institute sector allows us to better understand an important contributor to research in development in one of the largest economies in the world, an economy which ranks amount the top countries in R\&D spending as a fraction of GDP at $2 \% .{ }^{1}$ According to the China Statistical Yearbook on Science and Technology, in 2017 the research institute sector employed 462,000 people as R\&D personnel and contained 11.5\% of all R\&D personnel within the country. Additionally, the institutes contained $29 \%$ of all R\&D personnel engaged in basic research. The sector spent 243 billion RMB on $R \& D$ and this represented $14 \%$ of all $R \& D$ spending for the country. More importantly, the institute sector represented $40 \%$ of all expenditure for basic research and received 605 of all government R\&D funding. The sector also applied for 43,426 invention patents in 2017 and were granted 24,283 invention patents. The sector was responsible for $6 \%$ of all invention patents granted in 2017. Given the research institutes substantial contribution to Chinese R\&D, we are motivated to better understand this sector.

The rest of the paper proceeds as follows. Section two gives background information on the restructuring on the research institutes and section three describes our distinctive data set. Section four contains the main empirical results and section five concludes.

\section{Background on Restructuring}

The Chinese Ministry of Science and Technology (MOST) commenced a reclassification and reorientation of its approximately 4,000 research institutes in $1999 .{ }^{2}$ These research institutes

\footnotetext{
${ }^{1}$ All statistics in this paragraph are for 2017 and come from the China Statistical Yearbook on Science and Technology 2018, tables 20-1 and 20-2. See: http://www.stats.gov.cn/tjsj/ndsj/2018/indexeh.htm .

${ }^{2}$ MOST (2006), p. 26.
} 
were a substantial force in China's output of both basic research and $R \& D$, were heavily financed by government entities, and were overseen by central, provincial and local government institutions. As many of these institutes had branched out from basic research into more commercial activities or more non-profit service provision activities the ministry sort to reclassify institutes according to their primary focus and reallocate public funds to those engaging in basic research. To this end institutes were either converted to one of three types: science and technology enterprises, nonprofit research institutes and non-profit, non-research institutes. The S\&T enterprises were expected to focus on commercial research application and support themselves less with government grants. The non-profit research institutes were those most focused on basic research and expected to receive government support. The non-profit, non-research institutes were mainly focused on using current research to improve social or economic conditions. However, more than half the research institutes remained unconverted with no clarification of their purpose. It is of these institutes we are primarily concerned with in this paper. Specifically, we investigate if the unconverted institutes have kept pace with the converted institutes or if they have been left behind with unclear focus and purpose

Table 1 shows a count of the number of research institutes in our data (which we describe in more detail below). As our initial year, we use 1998, the year before restructuring began. First note that over time quite a few institutes have dropped out of the sample. The net change in the number of institutes was about -20\% from 1998 to 2012. While some research institutes may have closed, others merged together, and some became formal for-profit enterprises and were no longer tracked with the MOST statistical system. In addition to exits, we also observe research institutes entering the research system as well. Hence, the number of research institutes reflects the net change.

By 2001, 932 institutes had been reclassified, the bulk of these institutes were reclassified as S\&T enterprises. The number of S\&T enterprises continued to grow reaching 1,247 by 2012. Conversion to non-profit research institutes proceeded more slowly. While only 20 institutes were converted by 2001, their number reached 305 by 2012. Finally, 85 institutes were converted to non-profit, non-research institutes in 2001 and institutes continued to be converted until there were 172 non-profit, non-research institutes in 2012. However, the majority of institute remained unconverted, with 2,085 institute remaining unconverted as of 2012. 


\section{Data}

In this paper we use a novel data set on China's system of research institutes. These data stem from a thorough survey, conducted annually, by the Ministry of Science and Technology and made available to us for analysis by the Chinese Academy of Science and Technology for Development (CASTED) at their facility in Beijing. In general, the data are quite complete and accurate as research institutes are legally obligated to complete the survey.

The data are a panel beginning in 1998 and ending in 2012. Additionally, institutes both exit and enter the sample over time. While a complete description of the data set, over 300 variables would be unnecessary we describe the key variables we use in our analysis.

The first set of variables are measures of the research institute's output. We observe total revenue or income of the institute. We also know the source of this revenue, specifically if it comes from science and technology (S\&T), production and management (P\&M), or other activities. A subset of S\&T income is government grant revenue.

Revenue may not be a precise measure of research institute output. The purpose of a research institute is to produce knowledge. Consequently, measures of paper publication and patenting may better capture the production of a research institute. To this end, we use data collected on the number of patents for which the institute has applied, the breakdown of these patents into utility and invention patents, the number of patents granted and the number of papers published by the research institute. Invention patents represent a more novel idea relative to utility patents which are closer to adaptations of existing technology.

Finally, we also use data on the various inputs the institute uses in the production process. We know the total amount of personnel at the research institute. We can categorize the employees as production and management, science and technology or other employees. Additionally, we know the number of R\&D employees (a subset of S\&T employees). The research institutes also use S\&T related intermediate inputs (for example conference expenses) and equipment and we have data on the amount spent on these inputs. 


\section{Results}

\subsection{Descriptive Statistics}

In this section we examine how unconverted institutes evolved relative to converted institutes. We classify each institute by one of four types: unconverted; S\&T enterprise (S\&T); non-profit research institute (NPN); and non-profit, non-research institute (NPNR). We assign types to each institute based on its conversion status during the last year we observe the institute in our data. We use this classification to keep the sample of unconverted institutes from changing due to institute conversion to one of the three types.

Figure 1: Number of Institutes

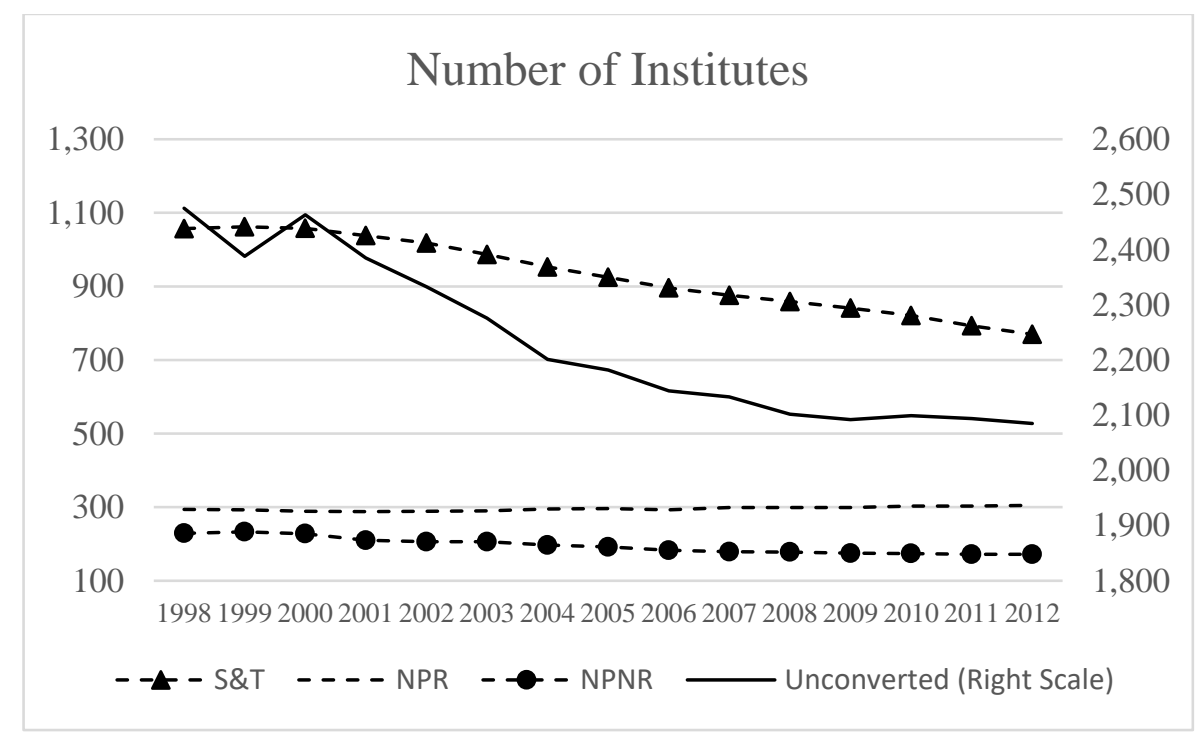

Note: This figure plots number of institutes present in each year by type. Type is defined as the institute's conversion status during their final year in the data set. The number of unconverted institutes is given by the right scale.

We begin, in figure 1, by examining the number of institutes in each category. Since category assignments are based on final status of the institute, the number of institutes changes only when institutes enter or exit the sample.

About 400 unconverted research institutes left the research institute system between 1998 and 2012 (right scale). This change is a 15\% decline implying an average net exit probability of $1 \%$ per year. The most likely reason an unconverted research institute would exit the system is that it 
closed. Though it is also possible that it merged with another institute or was spun off as a forprofit enterprise. In comparison, the number of NPR institutes is roughly constant over time. However, NPNR institutes have a higher probability of exit as do S\&T institutes. In these cases, a potential explanation for these high exit probabilities is that the core mission of these institutes is less likely to be research - for example in the case of S\&T institutes a focus on commercial applications of technology - and consequently they are exiting the research institute system.

Figure 2: Total Revenue of Research Institutes

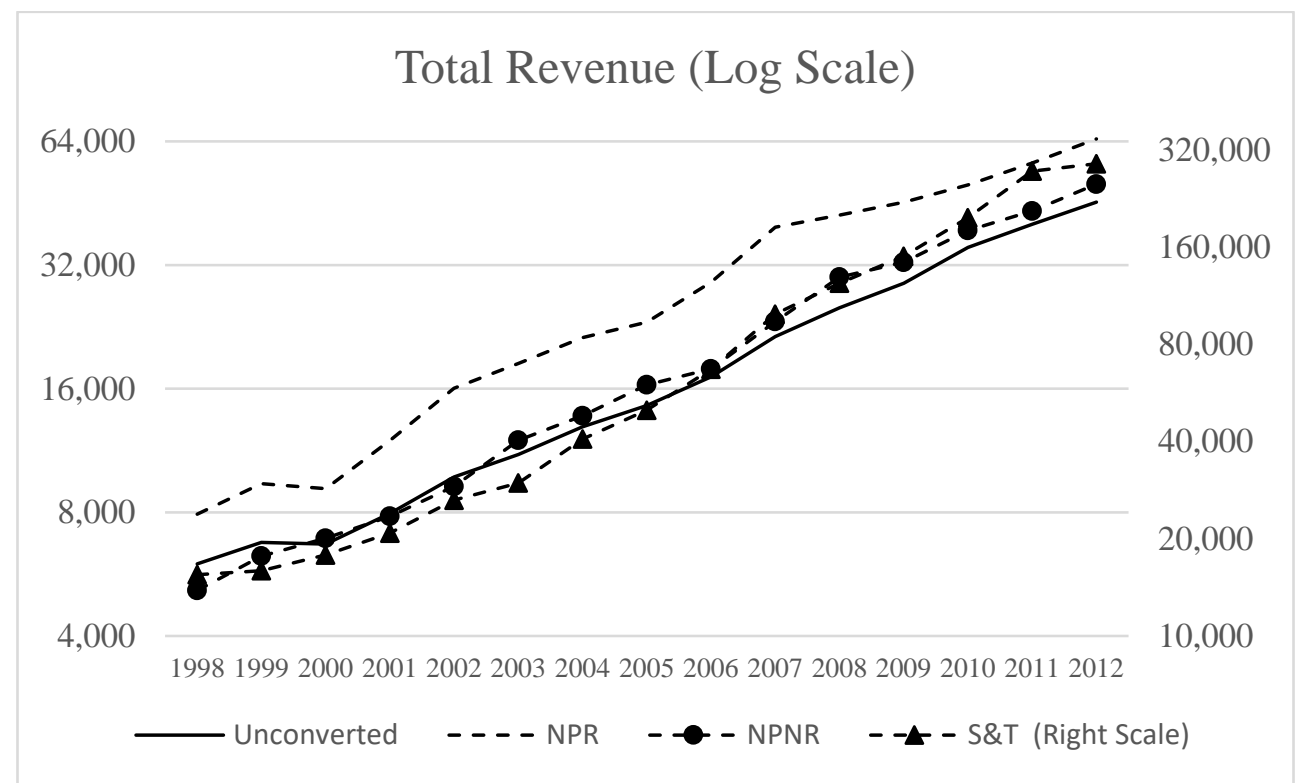

Note: This figure plots mean institute revenue in thousands of RMB by year and by institute type. Type is defined as the institute's conversion status during their final year in the data set. The revenue for the S\&T enterprises is given by the right scale. Both scales are log scales.

Next, in figure 2 we examine how total revenue has evolved over time for the unconverted institutes relative to the converted institutes. First, note that while the NPR institutes (dashed line) have on average 50\% more revenue than the unconverted institutes, they do not appear to have a substantially faster growth rate in revenue. In fact, the gap between the NPRs and the unconverted has been stable overtime. Revenue for the NPNR institutes is almost identical to the unconverted. On the other hand, the S\&T institutes (right scale) have had much larger revenue growth. This result is to be expected as S\&T institutes are driven more by commercial applications.

Our next question is if the unconverted institutes have seen changes in the sources of their revenue relative to converted institutes. There are two main sources of revenue for the research institutes: 
revenue from science and technology related activities (S\&T) and revenue from product production (P\&M). A subset of science and technology revenue come from government grants.

Unconverted institutes receive almost all their income from S\&T activities, over 90\% There has been no noticeable trend in this share over time. This number is very close to the revenue share for the NPR and the NPNR institutes. Like the non-profit research institutes, unconverted institutes have received an increasing share of their income from government grants over time. We therefore find little evidence that unconverted institutes are seeing diminished access to government funds.

Figure 3: Revenue Shares

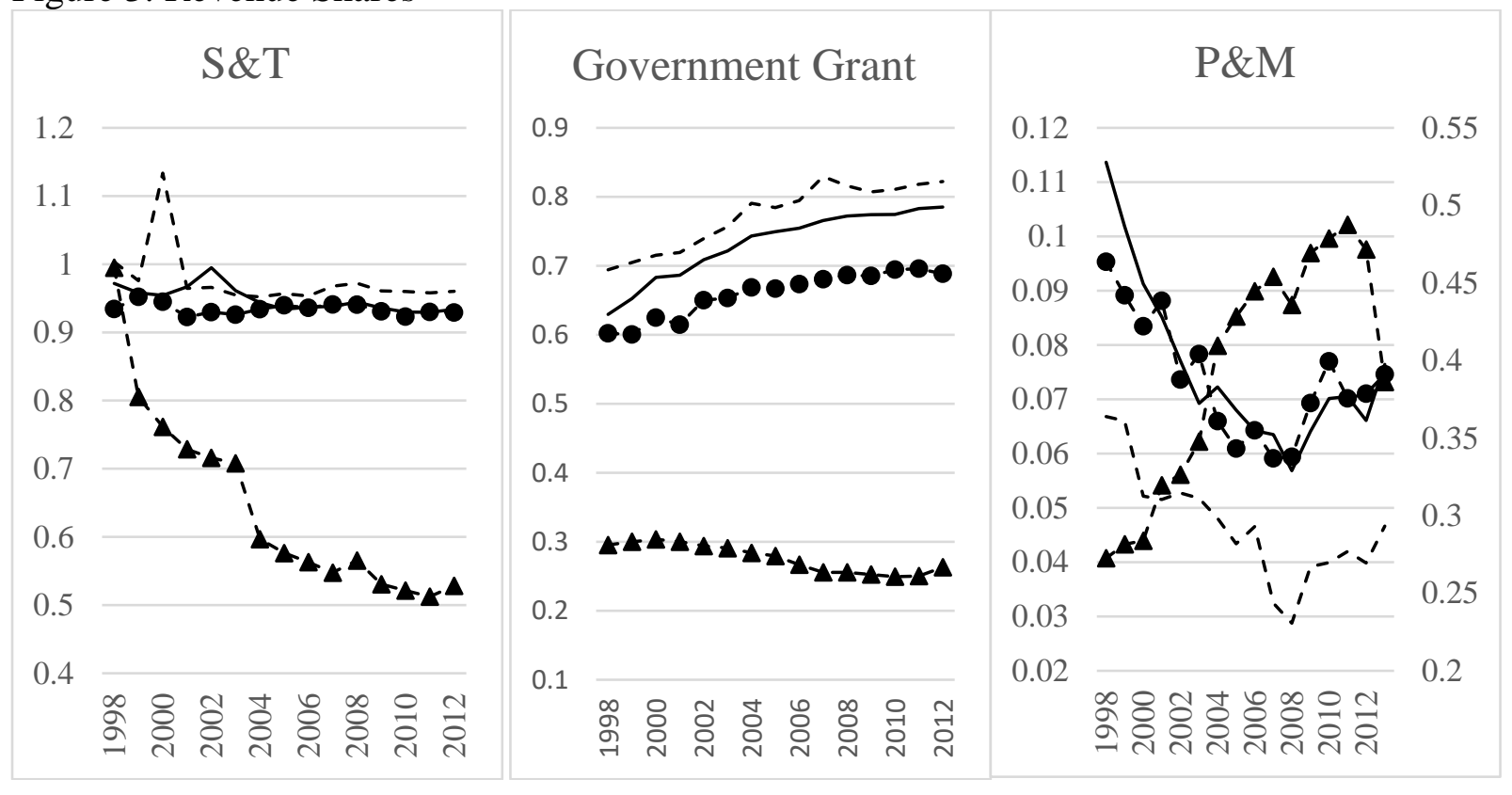

\section{Unconverted ------ NPR --•-- NPNR -- $\triangle$-- S\&T (Right Scale)}

Note: This figure plots mean revenue share for three possible sources of revenue, science and technology (S\&T), government grants, and production and management (P\&M) in each year by institute type. Type is defined as the institute's conversion status during their final year in the data set. The revenue for the S\&T enterprises is given by the right scale for P\&M revenue.

Figure 4 plots the number of personnel employed in research institutes and the break-down by type: production and management personnel (P\&M), science and technology personnel (S\&T) and research and development personnel (R\&D). Early in the sample, all research institutes reduced 
personnel which contributed to the productivity gains we demonstrate later. The drop-off was sharper for the NPR institutes than the unconverted institutes. ${ }^{3}$

Figure 4: Personnel

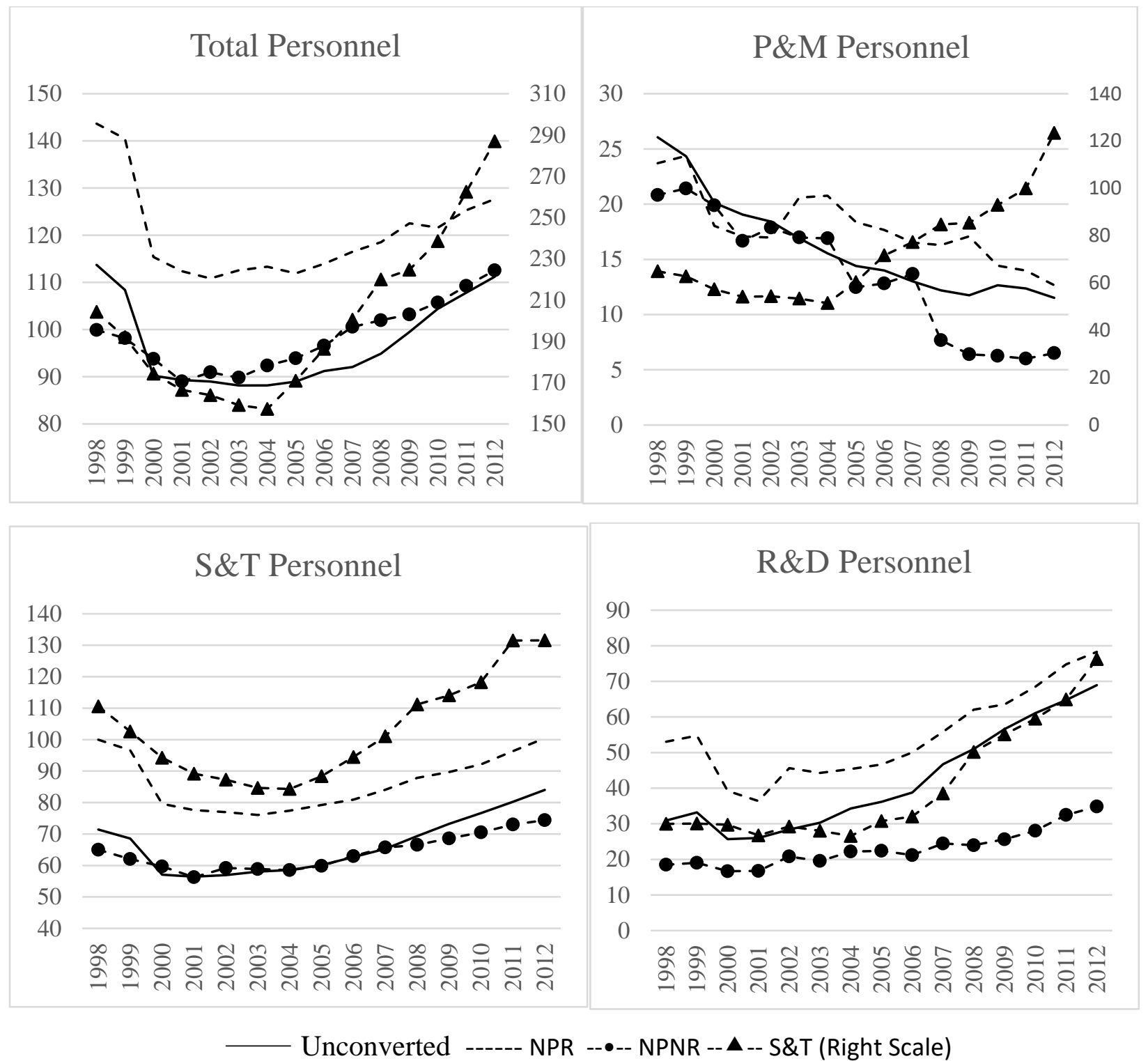

Note: This figures plots mean personnel in persons for total personnel and for three categories, science and technology (S\&T), production and management (P\&M), and research and development (R\&D) in each year by institute type. Type is defined as the institute's conversion status during their final year in the data set. The count for the S\&T enterprises is given by the right scale for P\&M personnel.

\footnotetext{
${ }^{3}$ We believe that the reason for the initial decrease in personnel was due to government budget pressures which required research institutes to cut back on personnel. However as economic pressures lifted post China's entrance into the WTO, more funds were made available to hire S\&T personnel.
} 
However, beginning in 2000 both the NPR institutes and the unconverted institutes increased their number of personnel by about 20 employees on average. Both these institutions reduced their employment of P\&M personnel and increased employment of S\&T workers primarily by employing R\&D employees. Consequently, it appears that unconverted institutes did not struggle to keep employees or hire new personnel. Notably, the S\&T institutes look quite different as they increased their commercial outlook by hiring more production and management workers.

Figure 5: Inputs

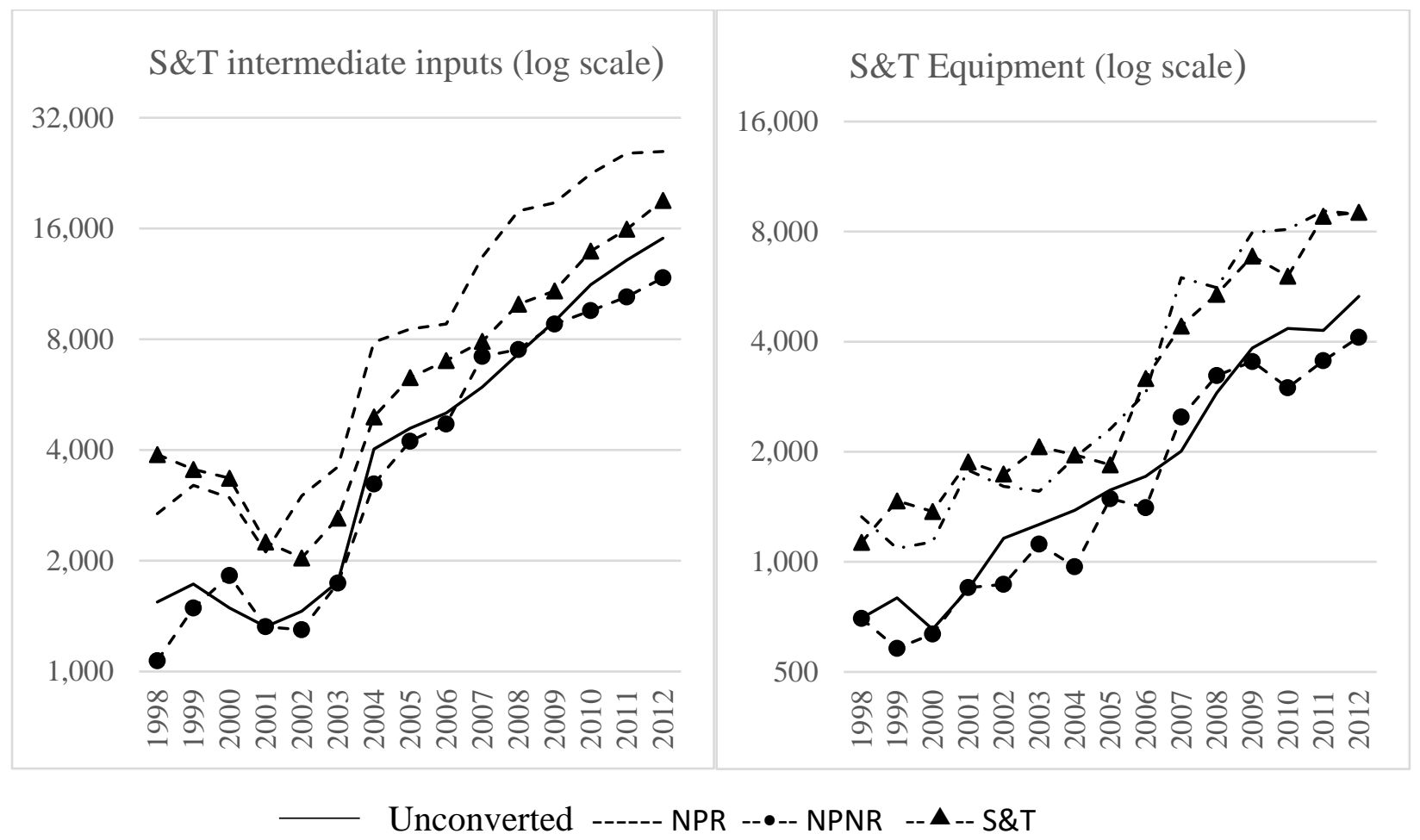

Note: This figure plots mean inputs in thousands of RMB, first S\&T intermediate inputs and then S\&T equipment, by year and institute type. Type is defined as the institute's conversion status during their final year in the data set. Plots use a log scale.

Unconverted research institutes may face difficulty in obtaining inputs for their research production. For example, inputs like materials or funding for conference travel or equipment for scientific experiments. Figure 5 presents the change over time in the monetary value of inputs and equipment used by the various research institutes using a logarithmic scale. There is a noticeable gap between the NPR institutes and the unconverted institutes. The level of inputs and equipment available to the unconverted institutes is like that of the NPNR institutes. However, the trend growth rate in inputs is not very different across the three groups. Resultingly, the gap between the 
NPR institutes and the unconverted in terms of the value of inputs and equipment between the two has grown larger over time.

Figure 6: Patent Applications

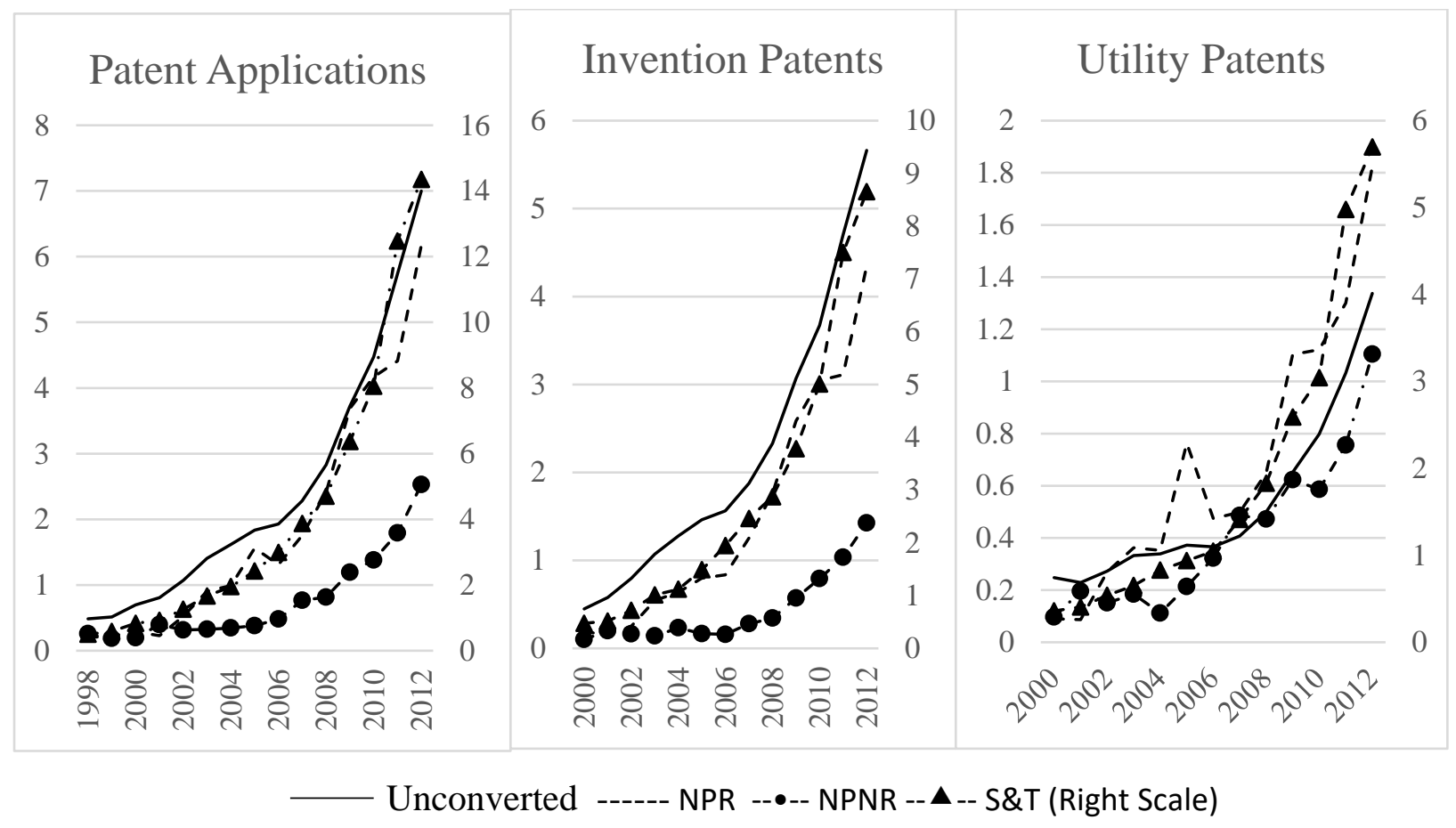

Note: This figure plots the average number of patent applications across institutes by year and type. Type is defined as the institute's conversion status during their final year in the data set. Total patent applications are in the first panel. These applications are then broken into invention and utility patents. S\&T institutes patenting averages are given on the right scale.

The main goal of a research institute is to produce knowledge. Knowledge by itself is difficult to measure and certainly hard to value. In this paper we use two measures of knowledge: patenting and the publication of scientific papers. Figure 6 plots the number of patent applications by year and institute type. Apart from the S\&T institutes, the unconverted institutes apply for more patents than the other types of institutes. On average, in 2012, the unconverted research institutes apply for 7 patents per year while the NPR institutes apply for about 6. Both types of institutes have seen large growth in patent applications after having produced less than one on average in 1998. Interestingly, unconverted research institutes apply for more invention patents (which represent a more novel idea) than utility patents (which involves adapting an existing invention). Based on these measures, the unconverted research institutes have kept pace with the converted institutes. 
Figure 7: Patents Granted and Papers Published

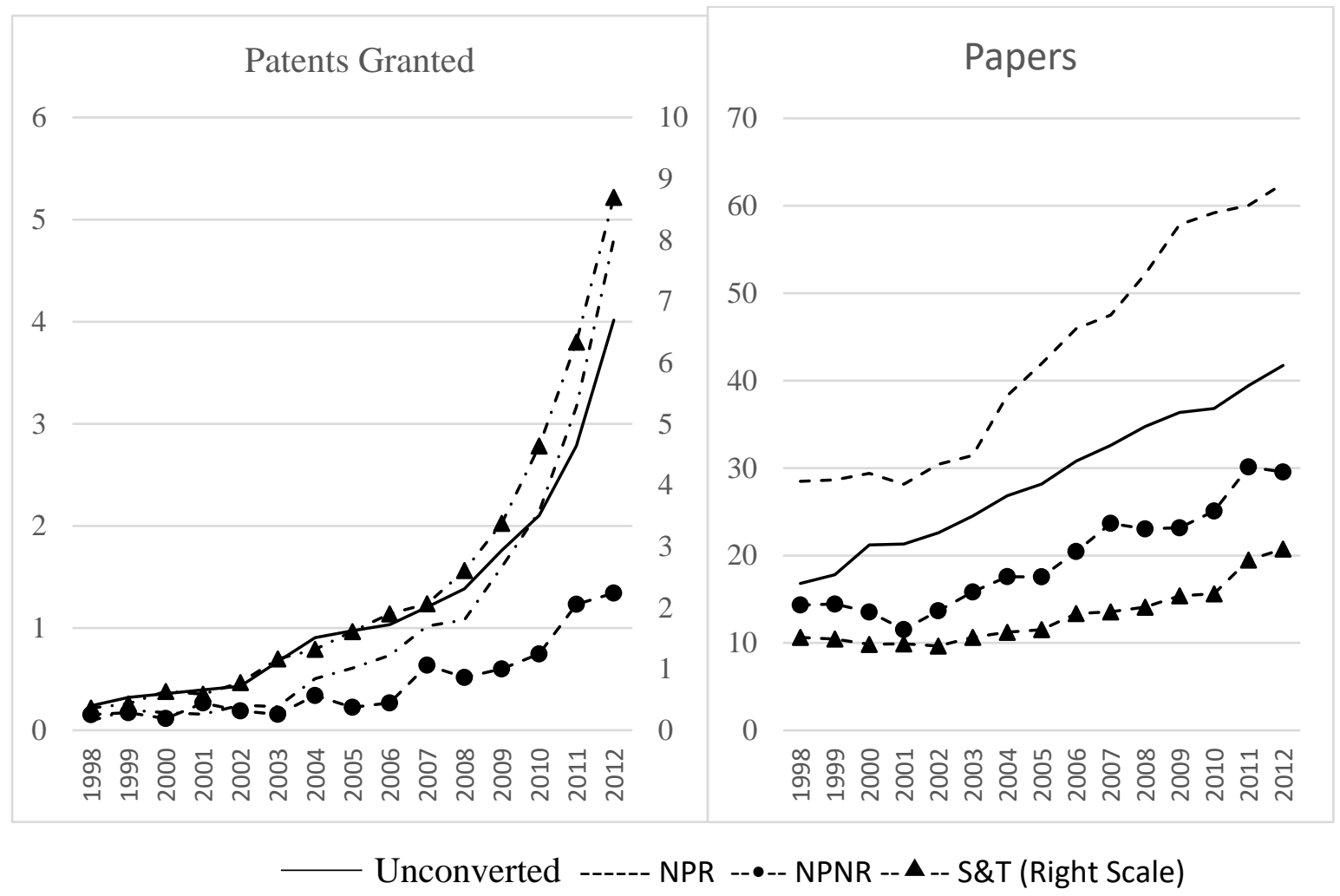

Note: This figure plots the average number of patents granted and papers published across institutes by year and type. Type is defined as the institute's conversion status during their final year in the data set. S\&T institutes patenting averages are given on the right scale.

However, when it comes to more definite knowledge-based accomplishments, NPR institutes have outpaced the unconverted institutes. Turning out attention to patents actually granted and scientific papers published (figure 7) we see that growth in patents granted and papers published grew faster among the converted NPR institutes than the unconverted.

Finally, we examine productivity of the research institutes. We use three measures of productivity: patent applications per 100 R\&D employees, papers per 100 R\&D employees and total revenue per employee. Again, the unconverted research institutes have not kept pace with the NPRI institutes. While patent applications per $100 \mathrm{R} \& \mathrm{D}$ workers was similar across the two types in 1998, by 2012 the NPR institutes had a clear lead in patent applications producing about 9 per 100 $\mathrm{R} \& \mathrm{D}$ employees compared to 7 for the unconverted. 
Figure 8: Productivity

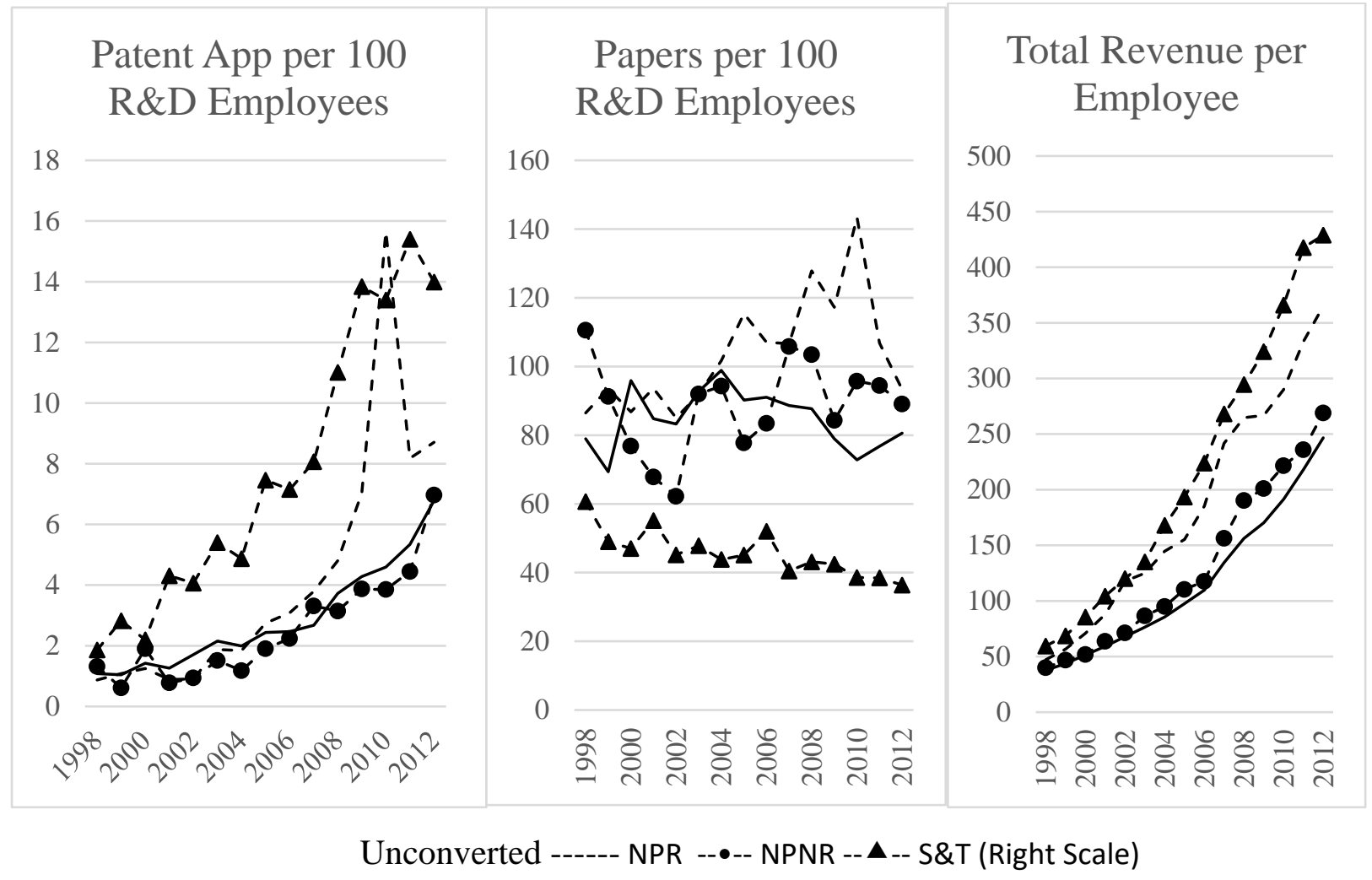

Note: This figure plots the average number of patent applications per $100 \mathrm{R} \& D$ employees, scientific papers published per $100 \mathrm{R} \& \mathrm{D}$ employees and total revenue per employee across institutes by year and type. Type is defined as the institute's conversion status during their final year in the data set.

Again, when we measure papers published per 100 R\&D employees the NPR institutes dramatically increase their productivity. They far outpaced the unconverted institutes from 2005 to 2011 though there is some evidence of conversion towards the end of the sample. Similarly, for total revenue per employee, the NPR institutes have seen greater growth than the unconverted. For all these productivity measures, the unconverted institutes closely resemble the NPNR institutes in their productivity levels.

\subsection{Regression Analysis}

In this section we perform a difference-in-difference analysis to compare changes in outcomes for the unconverted institutes relative to all the other institutes.

To perform this analysis we estimate the following equation:

$$
y_{i, t}=\alpha+\beta X_{i, t}+\delta_{0} * S_{i}+\delta_{1} * \operatorname{POST}_{\mathrm{t}}+\delta_{2} * \mathrm{~S}_{\mathrm{i}} * \mathrm{POST}_{\mathrm{t}}+v_{i, t}
$$


In this regression, $y_{i, t}$ represents our various outcome measures. These outcomes include total revenue and share of revenue from the three different sources: science and technology activities, government grants, and production and management activities. Additionally, we use patent applications, invention and utility patent applications, patents granted and papers published.

$X_{i, t}$ are various control variables. For our revenue regression we use (the log of) total personnel, S\&T equipment and S\&T intermediate inputs. We also include the share of S\&T personnel and P\&M personnel in total personnel. Since patenting is more dependent on research and development $(R \& D)$ personnel we use the share of $R \& D$ personnel and the share of $R \& D$ equipment and $R \& D$ inputs in place of the other shares in the revenue regression. ${ }^{4}$

$\mathrm{S}_{\mathrm{i}}$ is a vector of three indicator variables marking the conversion status of the institute during the final year it is present in our data. The first indicator variable indicates that the institutes was eventually converted to an S\&T institute. The second indicator variable indicates that the institute was eventually converted to an NPR institute. The third indicator variable indicates that the institute was eventually converted to a NPNR institute. The never converted institutes are the omitted group.

POST is an indicator variable for the year being one of the last three in our sample: 2010, 2011 or 2012. $\mathrm{S}_{\mathrm{i}} * \mathrm{POST}_{\mathrm{t}}$ represent three variables, the product of each of the status indicator variables with the time indicator.

For our regression we use only data from 2000-2002 and 2010-2012. This choice allows us to capture the average changes in outcomes over this ten-year period by type of institute. To interpret the regression, note that $\delta_{0}$ tells us the average difference in the outcome variable for the various institute types relative to the unconverted institutes (controlling for the $X_{i, t}$ variables) in the preperiod. $\delta_{1}$ tells us the average difference in the outcome from the initial period to the final period for the unconverted institutes. $\delta$ 2 gives the change in the outcome for the various types of institutes relative to the pre-period and the unconverted institutes.

As such, $\delta_{2}$ are our coefficients of interest. They tell us how each type of institute evolved relative to the unconverted. If a $\delta_{2}$ is positive, then the unconverted have fallen behind relative to the corresponding converted type. However, if a $\delta_{2}$ is negative, the unconverted have gained relative to the corresponding converted type. Therefore, one can see how the regression analysis adds to the graphical analysis in the previous subsection. We are now able to test for statistically significant

\footnotetext{
${ }^{4}$ As inputs may affect outputs with a lag all these variables are entered as 3-year moving averages, lagged one year.
} 
differences and also more accurately measure the effect of conversion type as we can control for institute inputs.

Table 2 contains the regression results for the revenue measures. First, we see that increased total personnel is associated with an increase in revenue. Specifically, a $10 \%$ increase in personnel corresponds to a $7 \%$ increase in total revenue. However, the larger the fraction of P\&M personnel the lower is revenue. S\&T equipment and intermediate inputs also relate to increased revenue. Based on these controls we now evaluate how the unconverted compare to the various converted institutes and how their relative position has changed over time.

The post indicator is positive implying increased revenue for the unconverted institutes on average over the decade of the 2000s. We see positive coefficients for the S\&T and NPR indicators and a negative coefficient for the NPNR indicator. Therefore, on average S\&T and NPR institutes have higher levels of revenue and productivity (since we control for inputs) while the NPNR institutes have slightly lower productivity.

Finally, turning our attention to the interaction terms we see that revenue grew $34 \%$ more for the S\&T converted institutes and 12\% more for the NPNR institutes. However, revenue grew less for the NPR institutes relative to the unconverted. This last result is somewhat surprising as the previous figures indicated that the NPR institutes had slightly higher revenue growth relative to the unconverted. Since we are controlling for inputs here, we interpret this result as implying that inputs increased relatively more in the NPR institutes explaining the increase in revenue. Indeed, when we re-run the regression (results available upon request) without the input controls we find that revenue growth is no longer significantly different between the unconverted and the NPR institutes.

Turing to columns 2-4 we see no difference in the revenue shares between the NPR and unconverted. NPR institutes and unconverted institutes receive about the same fraction of revenue from S\&T activities and government grants. Therefore, the unconverted do not seem to need to branch out into more commercial activities to make up for any loss of access to S\&T projects and funding.

One potential concern with our results would be that there is selection bias over time due to the exit of firms from the dataset. For example, it is possible that the weakest unconverted firms are exiting the sample and therefore artificially inflating the performance of the remaining sample. On the other hand, some firms exit the sample because they are more able to generate commercial revenue and so it is possible that actually the stronger firms exit. 
To examine if this type of survivorship bias is an issue in out analysis, columns 5-8 repeat the previous analysis but using only the sample of institutes that never exit the sample. The results are quite similar to the full sample case. Accordingly, we conclude that the differences among categories of institutes is not caused by the exit of weaker institutes over time.

Table 3 contains the regression analysis for the patenting measures. These results broadly confirm the patenting results based on the figures in the previous section. While the unconverted tend to patent slightly more than the other types of institutes there is little difference in how patent applications changes over time. Relative to the NPR institutes there was no change in patent applications from the pre and post-period. However, the unconverted had higher patent application growth relative to the NPNR institutes. Again, we see that relative to the unconverted the NPR institutes apply for fewer invention patents and more utility patents. We also see no difference in patents granted. However, in terms of paper production the unconverted have fallen noticeable behind the NPR institutes. Finally, exits of the institutes do not seem to drive the results. The numbers in columns 6-10, for the sample of institutes that never exit, are very close to the number in columns 1-5 which are for the full sample.

\section{Conclusion}

In this paper we have examined the fate of China's unconverted research institutes. In order to clarify the purpose of its research institute sector, China, beginning in 1999, reclassified its research institutes into three categories: S\&T enterprises, non-profit research institutes, and nonprofit, non-research institutes. However, a substantial majority of these institutes were not reclassified.

In this paper we examine the evolution of the unconverted research institutes relative to the converted research institutes. We found that, in general, the unconverted research institutes have kept pace with the converted institutes. The unconverted research institutes generated revenue and produced patents at the same rate as converted non-profit research institutes. However, the unconverted research institutes were at a higher risk of exit, produced fewer research papers, and saw smaller productivity gain than their converted counterparts.

Going forward, this paper suggests that the restructuring of China's research institutes was not a reform that benefited a few institutes at the expense of the many. In fact, many unconverted research institutes continued to be productive despite not being restructured. However, the paper raises questions about the efficiency of the research institute sector. For example, to what extent were the increased exits of research institutes post-reform detrimental to knowledge production? 
Additionally, are lower productivity institutes still being inefficiently supported by government funding. These results suggest measuring productivity in the research institutes sector and allocating funds to balance both efficiency and equity goals could improve performance of the whole sector. 


\section{References}

China Statistics Press, 1998-2012, China Statistical Yearbook, Beijing China.

Conroy, Richard, 1982 “China’s Local Scientific Research Sector: It’s Role, Impact and Future Prospects, The Australian Journal of Chinese Affairs, Vol. 7, pp.85-118.

Guan, J.C., Yam, R.C. and Mok, C.K., 2005. Collaboration between industry and research institutes/universities on industrial innovation in Beijing, China. Technology Analysis \& Strategic Management, 17(3), pp.339-353.

Hu, Mei-Chih \& John Mathews, 2008, “China's National Innovative Capacity,” Research Policy. 37. 1465-1479.

Jiang, Renai, Daniel L. Tortorice \& Gary H. Jefferson, 2016. "Restructuring China's research institutes," The Economics of Transition, The European Bank for Reconstruction and Development, vol. 24(1), pages 163-208, January.

Li, J., 2009. Global R\&D alliances in China: Collaborations with universities and research institutes. IEEE Transactions on Engineering Management, 57(1), pp.78-87

MOST (Ministry of Science and Technology Indicators), 2006 MOST (Ministry of Science and Technology Indicators), 2002. China Science and Technology Indicators.

Xiwei, Zhong \& Yang Xiangdong, 2007, "Science and technology policy reform and its impact on China's national innovation system, Technology in Society, Elsevier, vol. 29, pp 317-325.

Yuan, W., 2005. China's government R\&D institutes: changes and associated issues. Science, technology and society, 10(1), pp.11-29. 
Table 1: Summary Statistics on the Restructuring of China's Research Institutes

$\begin{array}{llllll}1998 & 2001 & 2004 & 2007 & 2010 & 2012\end{array}$

\begin{tabular}{lcccccc} 
Number of Institutes & 4055 & 3921 & 3646 & 3487 & 3397 & 3332 \\
Restructured & 0 & 932 & 1230 & 1242 & 1266 & 1247 \\
S\&T enterprise & 0 & 827 & 918 & 864 & 818 & 770 \\
Non-Profit Research Institute & 0 & 20 & 170 & 225 & 280 & 305 \\
Non-Profit Non-Research Institute & 0 & 85 & 142 & 153 & 168 & 172 \\
Net Decrease in Number of Research Institutes & & 134 & 409 & 568 & 658 & 723 \\
\hline
\end{tabular}

Note: This table gives the number of research institutes by year and the number converted to each type. 


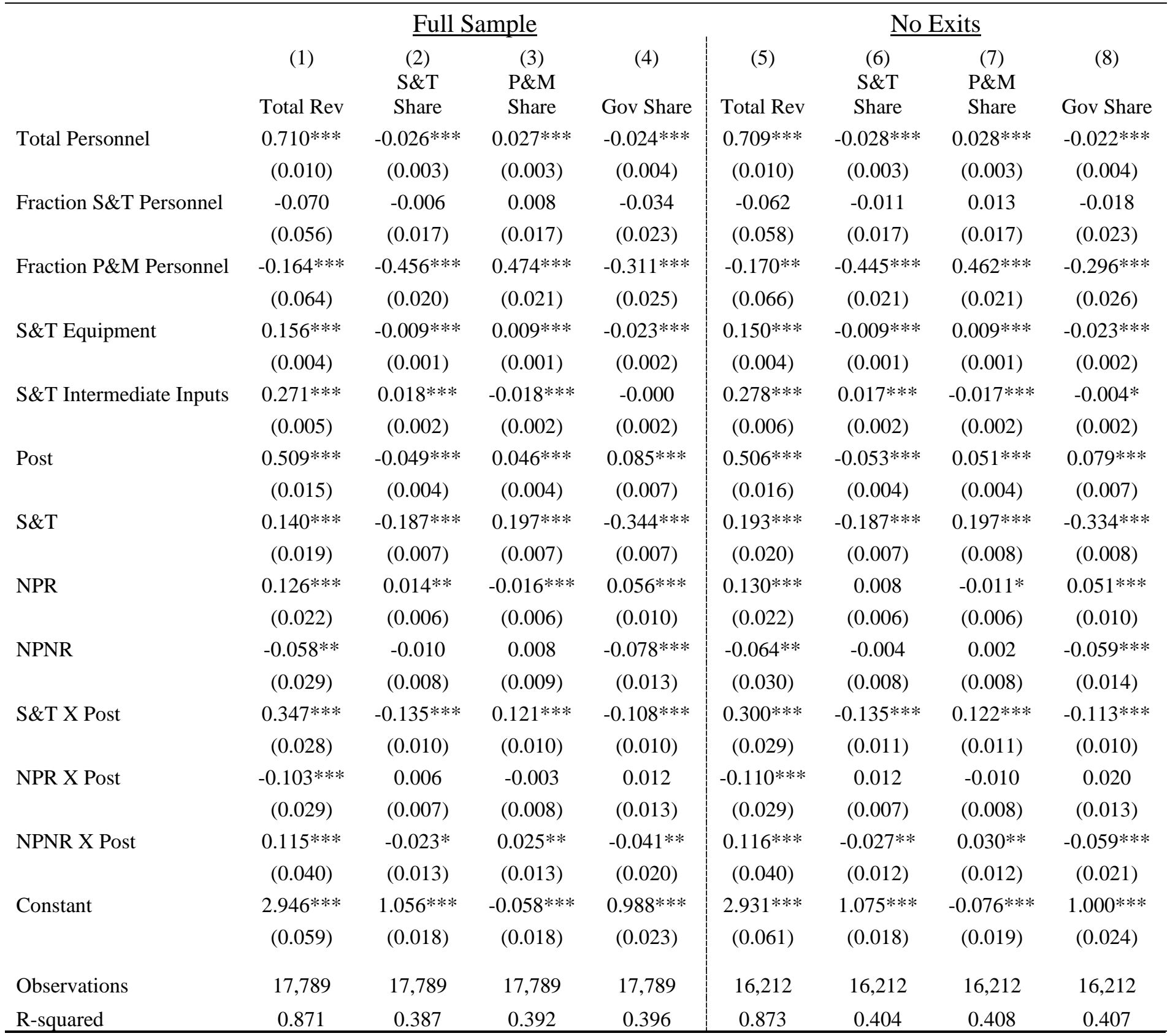

Note: All variables except fractions and binary variables are in logarithms. Post is an indicator that the year is 2010 or later. S\&T indicates an institute that was eventually converted to an S\&T enterprise. NPR in the same for a non-profit research institute. NPNR is the same for a non-profit, non-research institute. Robust standard errors in parentheses. ${ }^{* *} \mathrm{p}<0.01,{ }^{* *} \mathrm{p}<0.05,{ }^{*} \mathrm{p}<0.1$. 
Table 3: Patenting and Paper Results

\begin{tabular}{|c|c|c|c|c|c|c|c|c|c|c|}
\hline & \multicolumn{5}{|c|}{$\underline{\text { Full Sample }}$} & \multicolumn{5}{|c|}{ No Exits } \\
\hline & App & Inv & Util & Pat Grant & Paper & App & Inv & Util & Pat Grant & Paper \\
\hline \multirow[t]{2}{*}{ Total Personnel } & 0.087 & -0.485 & 0.571 & 0.273 & 0.900 & 0.287 & -0.406 & 0.693 & 0.294 & 1.603 \\
\hline & $(0.765)$ & $(0.456)$ & $(0.401)$ & $(0.396)$ & (1.976) & $(0.872)$ & $(0.510)$ & $(0.462)$ & $(0.445)$ & (2.124) \\
\hline \multirow[t]{2}{*}{ S\&T Personnel } & $5.427 * * *$ & $4.138^{* * *}$ & $1.289 * * *$ & $2.587 * * *$ & $23.509 * * *$ & $5.752 * * *$ & $4.394^{* * *}$ & $1.357 * * *$ & $2.857 * * *$ & $24.534^{* * *}$ \\
\hline & $(0.606)$ & $(0.518)$ & $(0.176)$ & $(0.291)$ & (1.852) & $(0.662)$ & $(0.568)$ & $(0.190)$ & $(0.302)$ & (1.985) \\
\hline \multirow[t]{2}{*}{ Frac. R\&D Per. } & $2.627 * *$ & $2.599 * *$ & 0.029 & $1.368^{* *}$ & $19.023^{* *}$ & $2.604^{* *}$ & $2.568 * *$ & 0.036 & $1.369 * *$ & $18.640 * *$ \\
\hline & $(1.045)$ & $(1.141)$ & $(0.140)$ & $(0.593)$ & $(8.775)$ & $(1.016)$ & $(1.120)$ & $(0.146)$ & $(0.585)$ & $(8.604)$ \\
\hline \multirow[t]{2}{*}{ S\&T Equip. } & $1.289 * * *$ & $1.064 * * *$ & $0.225^{* * *}$ & $0.631^{* * *}$ & $3.297 * * *$ & $1.415^{* * *}$ & $1.173 * * *$ & $0.243^{* * *}$ & $0.671^{* * *}$ & $3.506 * * *$ \\
\hline & $(0.117)$ & $(0.096)$ & $(0.041)$ & $(0.058)$ & $(0.322)$ & $(0.129)$ & $(0.105)$ & $(0.045)$ & $(0.062)$ & $(0.342)$ \\
\hline \multirow[t]{2}{*}{ Frac. R\&D Equip. } & $2.139 * * *$ & $2.029 * * *$ & 0.110 & $0.853^{* * *}$ & $15.410 * * *$ & $2.223^{* * *}$ & $2.175^{* * *}$ & 0.048 & $0.842 * *$ & $16.512^{* * *}$ \\
\hline & $(0.598)$ & $(0.580)$ & $(0.174)$ & $(0.319)$ & $(4.156)$ & $(0.621)$ & $(0.601)$ & $(0.185)$ & $(0.332)$ & (4.256) \\
\hline \multirow[t]{2}{*}{ S\&T Int. Inputs } & 0.161 & $0.187^{*}$ & -0.025 & 0.130 & $3.981 * * *$ & 0.188 & $0.224^{* *}$ & -0.036 & 0.152 & $4.433 * * *$ \\
\hline & $(0.177)$ & $(0.095)$ & $(0.097)$ & $(0.096)$ & $(0.424)$ & $(0.200)$ & $(0.106)$ & $(0.110)$ & (0.108) & $(0.455)$ \\
\hline \multirow[t]{2}{*}{ Frac. R\&D Inputs } & -0.026 & 0.012 & -0.039 & -0.021 & $0.930 *$ & -0.007 & 0.034 & -0.041 & -0.006 & $1.094^{*}$ \\
\hline & $(0.062)$ & $(0.047)$ & $(0.029)$ & $(0.034)$ & $(0.505)$ & $(0.066)$ & $(0.051)$ & $(0.033)$ & $(0.036)$ & $(0.585)$ \\
\hline \multirow[t]{2}{*}{ Post } & $1.840^{* * *}$ & $1.419^{* * *}$ & $0.420 * * *$ & $1.062 * * *$ & $-2.809 *$ & $2.064^{* * *}$ & $1.525 * * *$ & $0.539 * * *$ & $1.207^{* * *}$ & $-4.021^{* *}$ \\
\hline & $(0.480)$ & $(0.390)$ & $(0.156)$ & $(0.216)$ & (1.645) & $(0.537)$ & $(0.420)$ & $(0.195)$ & $(0.247)$ & $(1.774)$ \\
\hline \multirow[t]{2}{*}{$\mathrm{S} \& \mathrm{~T}$} & $-3.388 * * *$ & $-2.540 * * *$ & $-0.848 * * *$ & $-1.536 * * *$ & $-31.807^{* * *}$ & $-4.142 * * *$ & $-3.083 * * *$ & $-1.058 * * *$ & $-1.980 * * *$ & $-36.548 * * *$ \\
\hline & $(0.475)$ & $(0.305)$ & $(0.228)$ & $(0.259)$ & (1.434) & $(0.576)$ & (0.364) & $(0.281)$ & $(0.307)$ & (1.608) \\
\hline \multirow[t]{2}{*}{ NPR } & $-4.654 * * *$ & $-3.691 * * *$ & $-0.962 * * *$ & $-2.396 * * *$ & $-15.007 * * *$ & $-4.660 * * *$ & $-3.721^{* * *}$ & $-0.939 * * *$ & $-2.375^{* * *}$ & $-16.551^{* * *}$ \\
\hline & $(0.405)$ & (0.309) & (0.138) & $(0.205)$ & (1.749) & $(0.426)$ & $(0.327)$ & (0.139) & $(0.216)$ & (1.849) \\
\hline \multirow[t]{2}{*}{ NPNR } & $-1.915^{* * *}$ & $-1.557 * * *$ & $-0.358 * * *$ & $-0.872 * * *$ & $-16.484^{* * *}$ & $-2.132 * * *$ & $-1.754 * * *$ & $-0.378^{* * *}$ & $-0.955 * * *$ & $-18.754^{* * *}$ \\
\hline & (0.389) & (0.289) & (0.117) & $(0.205)$ & (1.631) & $(0.449)$ & $(0.331)$ & $(0.136)$ & $(0.236)$ & $(1.774)$ \\
\hline \multirow[t]{2}{*}{ S\&T X Post } & $8.550 * * *$ & $4.297 * * *$ & $4.253^{* * *}$ & $4.764 * * *$ & -0.917 & $9.079 * * *$ & $4.658^{* * *}$ & $4.421^{* * *}$ & $5.139 * * *$ & 2.189 \\
\hline & (1.695) & $(1.107)$ & $(0.806)$ & $(0.838)$ & (2.167) & $(1.749)$ & $(1.140)$ & $(0.835)$ & $(0.863)$ & $(2.270)$ \\
\hline \multirow[t]{2}{*}{ NPR X Post } & -0.938 & $-1.327 * *$ & $0.389 * *$ & 0.427 & $13.988 * * *$ & $-1.375^{*}$ & $-1.667 * * *$ & 0.293 & 0.203 & $13.821 * * *$ \\
\hline & $(0.697)$ & $(0.588)$ & $(0.192)$ & $(0.395)$ & (3.296) & $(0.735)$ & $(0.620)$ & (0.198) & $(0.408)$ & $(3.341)$ \\
\hline \multirow[t]{2}{*}{ NPNR X Post } & $-2.908 * * *$ & $-2.787 * * *$ & -0.121 & $-1.458 * * *$ & 0.504 & $-2.789 * * *$ & $-2.672 * * *$ & -0.116 & $-1.419 * * *$ & 2.406 \\
\hline & $(0.709)$ & (0.572) & $(0.233)$ & $(0.378)$ & (3.381) & $(0.761)$ & $(0.607)$ & $(0.248)$ & $(0.404)$ & $(3.472)$ \\
\hline Observations & 17,792 & 17,792 & 17,792 & 17,792 & 17,792 & 16,213 & 16,213 & 16,213 & 16,213 & 16,213 \\
\hline R-squared & 0.095 & 0.095 & 0.047 & 0.112 & 0.322 & 0.100 & 0.100 & 0.049 & 0.118 & 0.331 \\
\hline
\end{tabular}

